\title{
Silver Nanoparticles (AgNP) impregnated filters in drinking water disinfection
}

\author{
Alexandru Rus ${ }^{1, *}$, Vasile-Dănuț Leordean ${ }^{1}$ and Petru Berce ${ }^{1}$ \\ ${ }^{1}$ Technical University of Cluj-Napoca, Department of Manufacturing Engineering, \\ B-dul Muncii 103-105, 400641, Cluj-Napoca, Romania
}

\begin{abstract}
This paper describes how simple portable devices could eliminate water pathogens by using Silver Nanoparticles, based on their antimicrobial properties. Recent studies indicated that silver nanoparticles can achieve up to $100 \%$ antibacterial activity removal. Results are showing that Silver Nanoparticles retention in the filter structure, E. coli bacteria removal, water quality and water flow rate must be evaluated as main efficiency indicators of the designed filters, in order to obtain the optimal filter. To apply the antimicrobial property of Silver in drinking-water treatment, a filter is produced using Additive Manufacturing techniques and coated with different concentrations of silver solutions.
\end{abstract}

\section{Introduction}

Today world is facing real challenges in meeting increasing demands of drinking water as the available supplies of freshwater are exhausting due to lack of rain, population growth and more stringent health based regulations. Clean water is vital to human health, while in countries such as India, $80 \%$ of the diseases are due to bacterial contamination of drinking water.

The most common techniques used for water treatment are using mostly chemical and physical agents such as chlorine and its derivatives, bromine $(\mathrm{Br})$, water sediment filters (fiber and ceramic), activated carbon, reverse osmosis etc. but the use of halogens has many problems because of their high toxicity and vapour pressure [1]. Nanoscience is currently widely investigated to be used in water purification. This new interdisciplinary subject is referring to the study of chemical and physical changes at nanoscale level $(1-100 \mathrm{~nm})$. Nanotechnology is currently used for developing new materials and devices [2] and it is also intensively investigated in water purification.

This paper is referring to the use of nanotechnology, specifically the use of silver nanoparticles (AgNP) in water purification purposes. It describes the properties and methods used for obtaining AgNP, the types of substrates used in general for AgNP filters and proposes a new filter structure.

\footnotetext{
*Corresponding author: alexandru.rus86@gmail.com
} 


\section{Methods for obtaining the Silver Nanoparticles (AgNP)}

Silver is a white metal characterized by its shimmering, soft proprieties, being a good electric and thermal conductor. Silver is also a therapeutic agent used in medicine for treating infectious diseases and surgical infections. [3] Silver may be found in different form/silver compounds, such as Silver Nitride $\left(\mathrm{AgNO}_{3}\right)$, Silver Chloride $(\mathrm{AgCl})$, Silver fulminate $(\mathrm{AgONC})$, etc. The most popular compound is Silver Nitrate $\left(\mathrm{AgNO}_{3}\right)$ used as the starting for synthesis other silver products and painting area. Silver Chloride $(\mathrm{AgCl})$ is used for potentiometric and $\mathrm{PH}$ testing equipment [4].

It is well known that noble metals are very resistant to severe conditions and exhibit unique properties when they are produced at nanoscale. [5] Metal nanoparticles like silver are particles raging from $1 \mathrm{~nm}$ and $100 \mathrm{~nm}$ with very good electrical, optical and thermal properties. [6] Silver nanoparticles (AgNP) have a good conductivity, are chemically stable, their catalytic activity has been proved as being a very good one and are used due to exceptional antimicrobial activity [7].

AgNP is one of the most popular nanoparticles due to its many applications and relatively low manufacturing costs. Some of the AgNP applications are described below Figure 1:

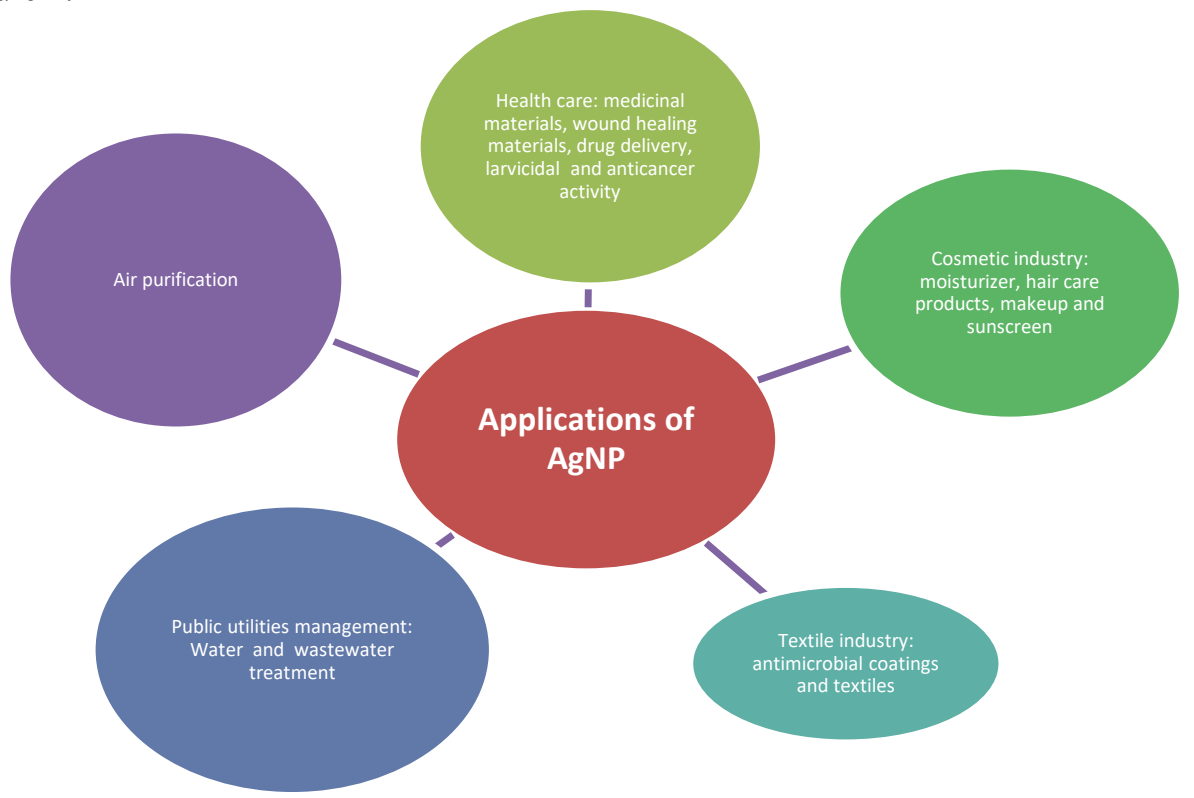

Fig. 1. Applications of AgNPs.

Currently, there are a lot of researches addressing the potential of AgNP for water treatment, mostly combined with filtration. Silver is either impregnated on domestic water filters either used in conjunction with copper ionization as a preventative measure against colonization of Legionella spp. A recent application is the usage of silver ions combined with copper and chlorine for swimming pools sanitation systems. [8] Among the advantages of this technology are: no odor, corrosion and no formation of unwanted oxidizing compounds. [9]

Over the time, different methods have been used to synthesize AgNP: biological, physical, and chemical. The more common methods are chemical and physical methods that produce pure and well-defined nanoparticles, but in general, the chemicals used in the synthesis are toxic, energy consuming and expensive [3]. 


\subsection{Chemical methods}

Chemical methods refer to the synthesis of AgNPs by using organic and inorganic reducing agents. An advantage of the chemical methods is the simplicity of preparing AgNPs in aqueous solution. The most common method of producing AgNP is the chemical reduction of $\mathrm{AgNO} 3$ dissolved in water with a reducing compound such as sodium citrate, borohydride, ascorbate, glucose, hydrazine, etc. [10] These agents have the role of reducing $\mathrm{Ag}+$ to metallic silver $(\mathrm{Ag} 0)$. During this process, it is important to use protective agents to stabilize the dispersion of the nanoparticles and avoiding their agglomeration. There are also other several methods of producing AgNPs such as: microemulsion techniques, UVinitiated photoreduction, electrochemical reduction, solution irradiation, microwaveassisted synthesis or cryochemical method [10].

\subsection{Physical methods}

Evaporation-condensation and laser ablation are the most common physical approaches for AgNPs synthesis having advantages such as the absence of solvent contamination in the prepared thin films and the uniformity of nanoparticle distribution. Thus, the result is pure and uncontaminated metal colloids.

However, these methods are also well known since the devices usually occupy large spaces and are expensive, they consume a great amount of energy while achieving the adequate temperature around the source material and require a lot of time to achieve thermal stability.

When using laser ablation in solution for AgNPs synthesis several factors such as laser wavelength, the duration of the laser pulses, the laser fluency, the ablation time duration and the effective liquid medium, with or without the presence of surfactants, should be taken into consideration [10]. Other physical methods for are referring to are thermal decomposition method, ceramic heating process, arc discharge technique [7].

\subsection{Biological methods}

There is a growing need to develop environmentally and economically friendly processes, which do not use toxic chemicals in the synthesis protocols [11]. In general these methods use: bacteria (Pseudomonas stutzeri AG259, Lactobacillus strains, etc.), fungi (Fusarium oxysporum, Aspergillus flavus), algae (Lyngbya majuscule, Spirulina subsalsa, Rhizoclonium heiroglyphicum, Chlorella vulgaris), plants (green tea (Camellia sinensis), alfalfa (Medicago sativa), lemongrass (Cymbopogon flexuosus), geranium (Pelargonium graveolens)). Synthesis of NPs using plants is very cost effective, and thus can be used as an economic and valuable alternative for the large-scale production of NPs

This method depends on a series of factors such as: the nature of the organisms, appropriate circumstances for cell growth and enzymatic activity, optimal reaction media, and appropriate choice of biocatalyst suitable to obtain the desired nanoparticle [10].

\section{Type of supports for AgNP filters}

Several researchers have shown that using different methods in preparing silver nanoparticles can lead to very good bacterial activity removal. Materials development is enhancing silver nanoparticles deposition on solid materials for the deactivation of microorganisms in water treatment [12]. In the case of drinking-water treatment, various forms of silver nanoparticles coated on materials/supports were investigated during the years: 
Sand impregnated with AgNP is less expensive, effective and can be self-constructed with limited local skills [13].

Zeolites as cation exchangers in water treatment, have increased in usage due to their availability, low cost, high surface area and sorption capacity, chemical inertness and low or null toxicity for human [14].

Fiberglass needs only a small amount of $\mathrm{Ag}$ for a strong bactericidal response against E. coli. The evidence suggests that the adhered Ag nanoparticles to the fiberglass substrate are active against bacteria in a filtration application. Falling desorption rates suggest the adsorption of Ag by the E. coli [15].

Activated Carbon filter was used as support for Silver Nano-particles from silver nitrate solutions using glucose as a reducing agent. The batch method showed that with the increase in contact time and the decrease in the bacterial count, complete inhibition was achieved. In column test, the prepared AgNPs/AC showed a complete bacterial reduction in synthetic water and actual polluted water samples. Data revealed a direct relation between Ag-NPs concentration and contact time toward bactericidal activity against E. coli which represented as an indicator for microorganism's pollution, whereas the concentration of AgNPs and contact time increased, bacterial counts of E. coli decreased and inhibition zone increased for all bacterial concentrations used [16].

Blotter paper allows microorganisms to meet the biocide, but attachment to the fiber surfaces limits the levels of silver in the effluent water. The primary purification mechanism is not the removal of bacteria from the effluent by filtration but rather the deactivation of bacteria as they percolate through the AgNP paper structure. Consequently, the filter effluent contains dead bacteria. The large pore size in the filter paper allows for reasonably rapid flow by gravity, without the need for pressure or suction [17].

Cellulose filters: Cellulose filter paper was coated with silver nanoparticles using a chemical reduction method, with sodium borohydride: silver nitrate ratios of 2:1 and 10:1. The efficiency this cellulose filter in E. coli removal ranged from $99 \%$ to $100 \%$. Moreover, the performance of the silver nanoparticle-coated cellulose filter paper was evaluated in terms of silver in the effluent and compliance with the drinking-water quality standards. Although further research is still necessary, the performance of silver nanoparticle-coated cellulose filter paper and its short and easy preparation method suggests its suitability as an antibacterial water filter during emergency situations [18].

Ceramic filters impregnated with silver nanoparticles were investigated in the laboratory and in the field in Guatemala. The addition of silver nanoparticles to the ceramic filters improved the performance for all mass percentages of sawdust relative to filter media without nanoparticle treatment. Filters with higher porosity achieved higher bacteria removal than those with lower porosity. After laboratory testing, ceramic filters were manufactured and distributed to 62 households. Over the course of the study, the average percent reduction in total coliforms and E. coli was around $90 \%$ and the average effluent concentration of ionic silver was 0:02 $\mathrm{mg}=\mathrm{L}$ (below the U.S. EPA standard of 0:1 $\mathrm{mg}=\mathrm{L}$ ) [19].

Polyurethane Foams, can be used for Silver nanoparticles coating in diverse forms. This material can be washed, dried, and stored for extended periods without the loss of nanoparticles. The performance of the material as an antibacterial water filter was checked and no bacterium was detected in the output water when the input water had a bacterial load of $1105-1106 \mathrm{CFU} / \mathrm{mL}$. The antibacterial action was also checked online for a flow rate of $0.5 \mathrm{~L} / \mathrm{min}$ and no bacterium detected, which suggests that domestic use of this technology is possible. The results are in line with the WHO requirements for drinking water. The experiments suggest the possibility of the use of this material in drinking water purification, air filtration, domestic and industrial air quality management, antibacterial 
packaging, etc. The chemicals involved in the synthesis of nanoparticles are commonly available, cheap, and non-toxic [20].

\section{Design of AM produced bottle cap filter}

The filter consists of a double threaded bottle cap, allowing contaminated water to flow from the support bottle into the receiver bottle. This is perforated by a 19,4-mm diameter cylindrical filter impregnated with silver nanoparticles. The AM techniques allow to produce a controlled porosity structure, which is influencing the efficiency of the filter in terms of silver retention in the filter, water flow rate and E. coli bacteria removal.
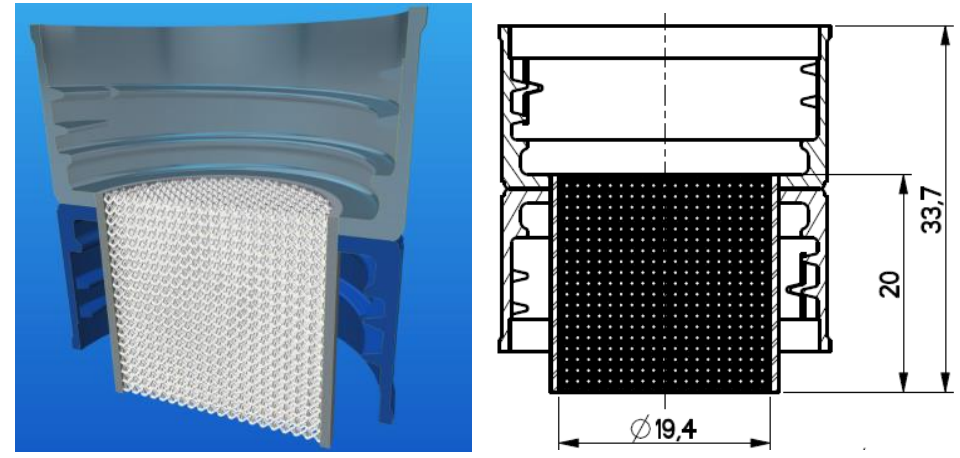

Fig. 2. AgNP Filtering bottle cap.

Dosoky et al. evaluated the bactericidal efficiency of AgNPs by its application in different concentrations to water sample, and allowed to interact with bacteria for different duration. Then, the bactericidal efficiency of AgNPs was determined by comparing the counted bacteria before and after the treatments resulting that the highest concentration of AgNP exhibited highest bactericidal efficiency in total bacteria count (TBC), where, after two hours, $0.1,0.05$ and $0.01 \mathrm{mg} / \mathrm{L}$ AgNP was found to be sufficient to inhibit 91.85, 89.14 and $74.92 \%$ TBC from surface water [21].

Therefore, the AgNP coating of the AM filter will be done using $0.1 \mathrm{mg} / \mathrm{L}$ concentration of AgNP. Water flow simulations through the designed filters must be evaluated to obtain indications on the optimal filter dimension and structure, to optimize the filter manufacturing process and the efficiency of filtration.

\section{Conclusions}

The research presented shows that different constructions of filters impregnated with silver nanoparticles can significantly improve water quality. The main intention is to analyse and develop an innovative filter with the optimal coating of AgNP which could completely remove pathogenic bacteria from test water. Moreover, further researches are needed to fully understand the behaviour of the designed filter structure in terms of porosity, AgNP coating, silver concentration in the effluent and E. coli removal from test water.

This research was supported by the AM-CIR project, PN-II-RU-TE-2014-4-1157, no. 37/01.10.2015 financed from the UEFISCDI by the Romanian Government. 


\section{References}

1. D. K. Tiwari, J. Behari, P. Sen, World Applied Sciences J, 3, 417-433 (2008)

2. $* * *$ https://www.sciencelearn.org.nz/resources/1640-nanoscience-explained, accessed on $4^{\text {th }}$ of July 2017

3. J. W. Alexander, 10, 3, 289-292 (2009)

4. $* * *$ http://ssnano.com/ag silver, accessed on $4^{\text {th }}$ of July 2017

5. Mü. Sökmen, S.Y. Alomar, C. Albay, Göü. Serdar, J. of Alloys and Compounds, 3 (2017)

6. $* * *$ http://www.mknano.com/Nanoparticles/Elements/Silver-Nanoparticles/, accessed on 28th of June 2017

7. K. Alaqad, T.A. Saleh, J. of Env. \& Anal. Tox., 6, 2-3 (2016)

8. L. Fewtrell, Silver: Water disinfection and toxicity, 2, 9 (2014)

9. ***http://www.watertechonline.com/silver-copper-have-anti-bacterial-effects/, accessed on 28th of June 2017

10. S. Iravani, H. Korbekandi, S.V. Mirmohammadi, B. Zolfaghari, Research in Pharmaceutical Sciences, 9 (6), 385-406, (2014)

11. Popa, I.M. Nicolai, V. Ceara, C. Boboc, C.A Danes, ICPE, EEA, 64, 2, 104-112 (2016)

12. L. Mpenyana-Monyatsi, L. H. Mthombeni, M.S. Onyango, M. N. B. Momba, Int J Environ Res Public Health, 9, 1, 244-271 (2012)

13. S.N. Mahmood, S. Naeem, N. Basit, T.H. Usmani, Envir. Tech., 14, 151-157 (1993)

14. Y Matsumura, K. Yoshikata, S.I. Kunisaki., T. Tsuchido, Appl. Environ. Microbiol. 69, 4278-4281 (2003)

15. G. Nangmenyi, Z. Yue, S. Mehrabi, E. Mintz, J. Economy, Nanotechnology, 20, 495505 (2009)

16. A.H.M. El-Aassar, M.M. Said, M. Abdel-Gawad, H.A. Shawky, Australian J of Basic and Applied Sciences, 7 (1), 422-432 (2013)

17. T. A. Dankovich, D. G. Gray, Envir. Sci Tech., 45, 1992-1998 (2011)

18. S.M. Praveena, L. S. Han, L.T.L. Than, A.Z. Aris, J of Experimental Nanoscience, 11, 17, 1307-1319 (2016)

19. E. N. Kallman, V. A. Oyanedel-Craver, J. A. Smith, J. Environ. Eng., 137, 407-415 (2011)

20. J. Prashant, T. Pradeep, Potential of Silver Nanoparticle-Coated Polyurethane Foam as an Antibacterial Water Filter, Wiley InterScience, DOI: 10.1002/bit.20368 (2005)

21. R. Dosoky, S. Kotb, M. Farghali, J. Adv. Vet. Anim. Res., 2 (2), 175-184 (2015) 